\title{
Mucinous Nonneoplastic Cyst of the Pancreas: A Novel Nonneoplastic Cystic Change?
}

\author{
Markus Kosmahl, M.D., Naoto Egawa, M.D., Sören Schröder, M.D., Fatima Carneiro, M.D., \\ Jutta Lüttges, M.D., Günter Klöppel, M.D. \\ Department of Pathology, University of Kiel (MK, JL, GK), Kiel, Germany; Department of Internal \\ Medicine, Tokyo Metropolitan Komagome Hospital (NE), Tokyo, Japan; Institute of Pathology (SS), \\ Hamburg, Germany; and Institute of Pathology, University of Porto (FC), Porto, Portugal
}

Cystic lesions and neoplasms of the pancreas are uncommon, but they are of special interest because they can usually be cured by resection. During the last decade, the spectrum of these tumors has increased considerably. We present a series of five cystic lesions of the pancreas that differ from all categories described so far. The patients affected by these tumors were three men and two women (mean age, 57 y). Four lesions were unifocal and involved the head of the pancreas; one was multifocal and involved the pancreatic head and tail. Grossly, these tumors presented as unilocular or multilocular thin-walled cysts that contained turbid fluid, or, in two cases, blood, and lacked any communication with the duct system. Microscopically, the cysts were lined by cuboidal to columnar mucin-producing cells, supported by a small band of dense fibrous stroma. Immunocytochemically, the epithelial cells were positive for cytokeratins 7 , 8, 18, 19, and 20 (except one), and Ca 19-9 but were negative for trypsin, CEA, synaptophysin, chromogranin A, calretinin, and $\alpha$-inhibin. In four of the five lesions, the epithelial cells expressed MUC5AC, and in one of the five, MUC1. MUC2 and MUC6 were not expressed in any of the lesions. The stromal cells lacked the nuclear progesterone positivity that is typical of mucinous cystic neoplasms. During a mean follow-up period of 2 years, there were no recurrences or cases of malignant transformation after resection. The results suggest that these cystic lesions are distinct from mucinous cystic neoplasms, the most important entity in the differential diagnosis. Because they may represent a nonneoplastic cystic change of the pancreas, we propose

Copyright (C) 2002 by The United States and Canadian Academy of Pathology, Inc.

VOL. 15, NO. 2, P. 154, 2002 Printed in the U.S.A.

Date of acceptance: October 30, 2001.

Address reprint requests to: Günter Klöppel, Ph.D., Department of Pathology, University of Kiel, Michaelisstrasse 11, 24105 Kiel, Germany; e-mail: gkloeppel@path.uni-kiel.de. the descriptive term mucinous nonneoplastic cyst for these tumors of unknown pathogenesis.

KEY WORDS: Cystic tumors, Mucinous nonneoplastic cyst, Pancreas.

Mod Pathol 2002;15(2):154-158

Cystic tumors of the pancreas may be either neoplastic or nonneoplastic. The predominant neoplastic types are intraductal papillary mucinous neoplasms, mucinous cystic neoplasms, serous cystic adenomas, and solid pseudopapillary neoplasms (1). The remaining cystic tumors (the term cystic tumor denotes any cystic lump, regardless of whether it is neoplastic or not) comprise neoplasms, such as acinar cystadenocarcinomas, cystic endocrine tumors, dermoid cysts, and ductal adenocarcinomas with cystic features $(2,3)$. They also include nonneoplastic lesions, such as lymphoepithelial cysts and other types that have been given various names but are poorly characterized (2, 4-6).

Recently, we observed a special type of cystic lesion of the pancreas composed of mucinous cells that were not supported by an ovarian-like stroma and did not show any obvious neoplastic potential. Here we report the clinicopathological features of a series of five cases of these recently observed, novel cystic lesions of the pancreas.

\section{MATERIALS AND METHODS}

The cases we studied were collected from the consultation files of the Department of Pathology at the University of Kiel. Four cases came from hospitals in Europe, and one came from Japan. Table 1 summarizes the most important clinicopathological data. In all patients, the tumors had been removed surgically.

The tissue of the cystic lesions was fixed in $10 \%$ formaldehyde, embedded in paraffin, and sectioned. The sections were stained with hematoxylin 
TABLE 1. Clinicopathological Data on Mucinous Nonneoplastic Cysts of the Pancreas

\begin{tabular}{ccclccc}
\hline No. & Age $(\mathrm{y})$ & Sex & \multicolumn{1}{c}{ Site } & Size & Uni-multilocular & Symptoms \\
\hline 1 & 20 & $\mathrm{f}$ & Head, tail & 3 & Multilocular & Obstructive jaundice, first resection \\
& & & & & Multilocular & Incidental finding \\
2 & 66 & $\mathrm{~m}$ & Head, body & 4 & Multilocular & Epigastric discomfort \\
3 & 72 & $\mathrm{f}$ & Head & 5 & Unilocular & Obstructive jaundice \\
4 & 60 & $\mathrm{~m}$ & Head & 3.5 & Multilocular & Abdominal pain \\
5 & 68 & $\mathrm{~m}$ & Head & & \\
\hline
\end{tabular}

f, female; m, male.

and eosin, periodic acid-Schiff with and without diastase digestion, and Alcian blue at pH 2.5. They were additionally stained using the avidin-biotin peroxidase complex technique and by employing monoclonal (M) or polyclonal (P) antibodies against cytokeratin 7 (CK7, M, 1:1000; DAKO, Copenhagen, Denmark); cytokeratins 8, 18, and 19 (CAM 5.2, M, 1:10, Becton Dickinson, Mountain View, CA); cytokeratin 20 (CK20, M, 1:20; DAKO); carcinoembryonic antigen (CEA, M, 1:20; DAKO); carbohydrate antigen 19-9 (CA 19-9, M, 1:40; kindly provided by Dr. H. Kalthoff, Kiel, Germany); the mucin antigens MUC1 (M, 1.100, NovoCastra, Newcastle, United Kingdom), MUC2 (M, 1:50; NovoCastra), MUC5AC (M, 1:500; Chemicon, Temecula, CA), and MUC6 (M, 1:100;NovoCastra); $\alpha$-inhibin (M, 1:10; Serotec, Oxford, United Kingdom); calretinin ( $\mathrm{P}, 1: 100$, Chemicon); trypsin ( $\mathrm{P}, 1: 1000$; our laboratory); progesterone receptor ( $\mathrm{P}, 1: 100$; Ventana, Strasbourg, France); synaptophysin (P, 1:100; Ventana); and chromogranin A (M, Ventana). The proliferative activity was assessed by staining the tissue with the antibody KiS5 (equivalent to Ki67). Appropriate positive and negative controls were systematically included.

\section{RESULTS}

\section{Clinical Findings}

One lesion was detected incidentally. Two patients presented with epigastric discomfort and pain, and the other two showed obstructive jaundice caused by compression and dislocation of the common bile duct by the cystic lesion. Computed tomography revealed a unilocular cyst (Fig. 1). In one case, endoscopic retrograde cholangiopancreatography was performed. It did not reveal any communication between the mass and the main pancreatic duct or biliary tract. None of the patients developed a tumor recurrence. All are alive and well (mean follow-up, $2 \mathrm{y}$; range, 1-8 y).

\section{Gross Pathology}

The tumors showed a macrocystic pattern. Their maximum diameter ranged from 3 to $12 \mathrm{~cm}$ (Table 1). They were well-circumscribed, round lesions that, on cut section, displayed either a unilocular cyst (one case) or multilocular cysts that were filled with turbid fluid or bloody material (Fig. 2). The multilocular cystic lesions were composed of two to four cysts that were separated by thin septa. All lesions involved the head of the pancreas. One patient additionally had a cystic lesion in the tail of the pancreas. In all cases, no communications of the cysts with the pancreatic duct or biliary system were found.

\section{Light Microscopy}

In four cases, the wall of the grossly visible cysts contained a few tiny microcysts. The cysts were lined by a single layer of cylindrical or cuboidal epithelial cells (Fig. 3A). There were also areas in which the epithelial layer was extremely flattened, and in one case this was the predominant appearance of the epithelium. There were no papillary or microglandular structures. The cytoplasm of the lining cells was eosinophilic and showed periodic acid-Schiff (without and with diastase digestion; Fig. 3B) and Alcian blue staining that was usually restricted to the apical portion. The nuclei were round to oval and lacked pleomorphic changes and mitotic figures. In one case, there was massive epithelial denudation because of a fresh hemorrhage filling the cyst with blood. In two cases, there were hemosiderin-containing macrophages in the cyst wall as signs of an old hemorrhage. The fibrous

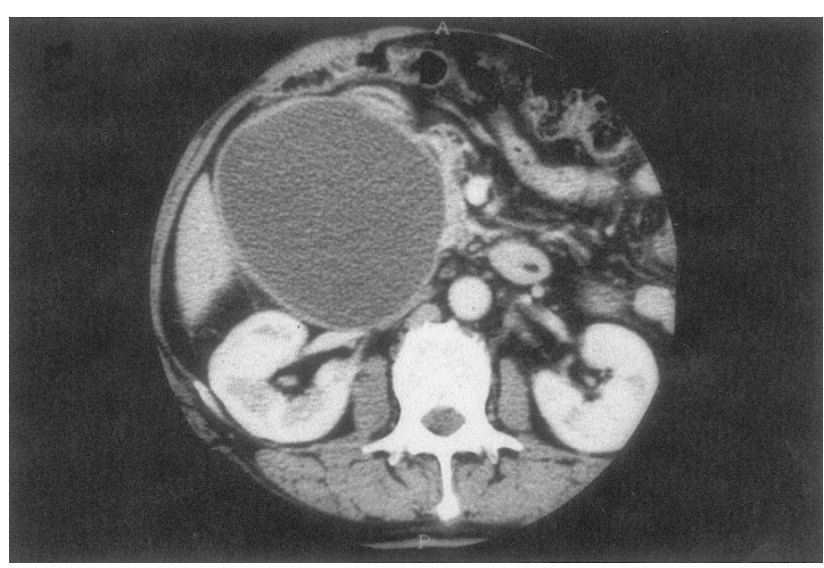

FIGURE 1. Computed tomography scan revealing a large cystic mass, about $12 \mathrm{~cm}$ in diameter, in the head of the pancreas, without communication with the pancreatic duct or biliary system (Patient 4). 


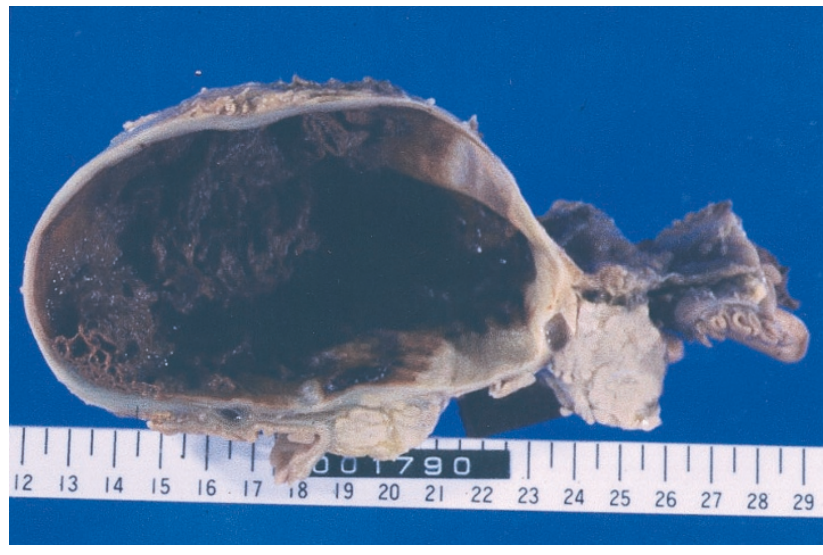

FIGURE 2. Macroscopic appearance. A unilocular cyst containing chocolate-colored old blood, with compression and dislocation of the common bile duct (same patient as Fig. 1).

stroma supporting the cysts was thin, band-like, and paucicellular with occasional hyalinization and, in one case, calcification and metaplastic bone formation. In three cases, the stroma showed scattered lymphocytes and macrophages. Because of the absence of islets of Langerhans, ductal elements, or nerve trunks in the cyst wall, the cystic lesions appeared well separated from the adjoining pancreatic parenchyma. In one case, the adjoining parenchyma contained multiple foci of adenomatoid hyperplasia. In the other cases, there were only single ducts displaying PanIN-1A and $1 \mathrm{~B}$ lesions (7, 8). Fibrotic changes were lacking.

\section{Immunocytochemistry}

Immunocytochemically, the cyst lining cells expressed the cytokeratins 7, 8, 18, 19, and 20 (except in one case) to a variable extent. CA19-9 was positive in all cases. In four of the five cases, the cyst lining cells were positive for MUC5AC, whereas only one case expressed MUC1 and none expressed MUC2 or MUC6. Carcinoembryonic antigen, trypsin, calretinin, $\alpha$-inhibin, vimentin, chromogranin A, and synaptophysin were also not expressed. Not only the epithelial layer but also the stromal cells were negative for the progesterone receptor. The proliferative activity of the epithelial cells, as assessed with KiS5, was $<1 \%$.

\section{DISCUSSION}

These cystic lesions, which we observed in the pancreas of five patients, were characterized by mucinous differentiation of the lining epithelium; lack of cellular atypia or increased proliferation; a thin rim of supporting, almost acellular stroma; lack of communication with the duct or biliary system; preferential localization in the pancreatic head; and no obvious sex predilection. Because of the absence of any neoplastic features, in other words, cellular atypia, increased proliferation, invasive growth pattern, and metastatic spread, we termed this change a mucinous nonneoplastic cyst (MNC).

The most challenging differential diagnosis of $\mathrm{MNC}$ is versus pancreatic retention cysts and mucinous cystic neoplasms (MCN), because both of these changes are lined by epithelium that is similar to that of MNCs.

Retention cysts are caused by obstruction of an interlobular pancreatic duct by an intraductal obstacle or a narrowing of its lumen. Intraductal obstacles are viscous mucin, as in cystic fibrosis; calculi, as in alcoholic chronic pancreatitis; or reactive or neoplastic epithelial proliferations, as in PanIN-1B lesions (7) or intraductal neoplasms (911). Narrowing of the lumen is caused by fibrosis, as in chronic pancreatitis, or by neoplastic infiltration of the periductal tissue, as in ductal adenocarcinomas or endocrine neoplasms (2). In all of these cases, the resulting retention cysts are rather small lesions, not larger than 0.5 to $1 \mathrm{~cm}$. In our cases, the cysts were large $(>3 \mathrm{~cm})$, and they were not associated with any of the conditions mentioned above. In particular, there was no pancreatic fibrosis or
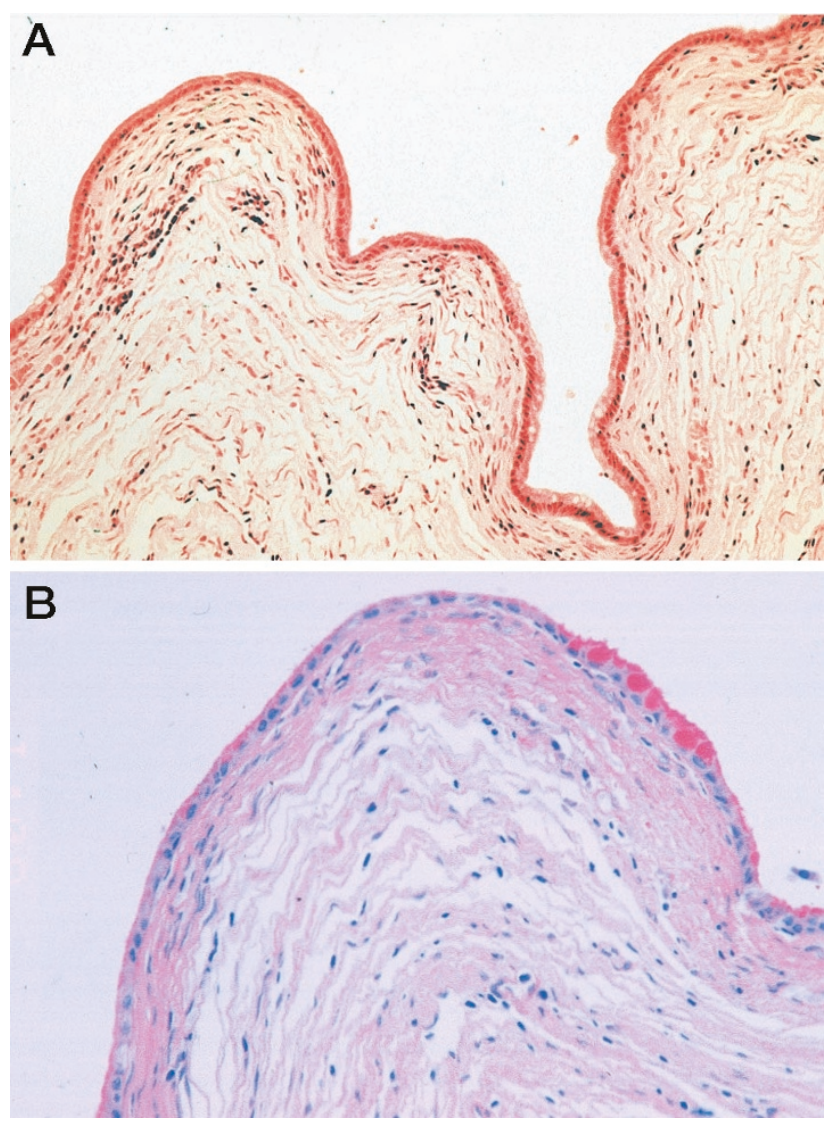

FIGURE 3. The cysts are lined by a single layer of cylindrical or cuboidal epithelial cells. Staining with hematoxylin and eosin (A) and periodic acid-Schiff (B). 
tumorous proliferations in the pancreatic tissue adjacent to the MNCs. Endoscopic retrograde pancreatography and careful gross preparation also excluded a communication with the pancreatic duct system.

The MCN of the pancreas, as classified by Compagno and Oertel (12) and described by many other authors (13-18), presents as a well circumscribed unilocular or multilocular cystic tumor, which, in $>90 \%$ of the cases, is localized in the body and tail of the pancreas of women (18), features that were missing in the MNCs. Further differences concern the histological findings. Although MCNs are also composed of columnar cells with mucinous differentiation that share with the epithelial cells of MNCs the periodic acid-Schiff and Alcian blue staining and the expression of a number of other markers (compare below), in MCNs the columnar cells may show all grades of cellular atypia and are supported by an ovarian-like stroma $(4,17)$, findings that are not observed in MNCs. However, MCNs and MNCs also have some features in common. Both express the cytokeratins that distinguish many pancreatic ductal cells, in other words, cytokeratins 7, 8, 18 and 19 (19). This cytokeratin spectrum also includes cytokeratin 20, which is not expressed in the normal duct epithelium of the pancreas (20) but was found in both MNCs and MCNs (data for MCNs are not shown). Of the mucin markers, MUC5AC was demonstrated in all but one MNC and was recently also observed in all MCNs (data not shown). These findings suggest that MNCs and MCNs have a similar epithelial phenotype but differ in their stromal component and in their potential for malignant cellular transformation.

No other cystic lesions and neoplasms of the pancreas (1) cause problems in the differential diagnosis of MNCs. Thus MNCs can easily be distinguished from intraductal papillary-mucinous neoplasms by their lack of communication with the duct system (21); from solid pseudopapillary neoplasms by their lack of female predominance, pseudocystic degeneration, and cellular features (22-24); from serous cystic tumors by their lack of serous differentiation (25); from paraampullary duodenal wall cysts by their location in the duodenal wall and submucosa $(2,26)$; and from the recently described acinar cystic transformation (5) and cystic endocrine tumors (27) by their lack of acinar or endocrine cell differentiation, respectively.

The cause and the development of MNCs are not known. It may be speculated that they are caused by a developmental defect of the pancreas, resulting in a focal cystic transformation of the duct system. The reason why the epithelial cells of MNCs differ from normal pancreatic ductal cells in their positivity for CK20 and MUC5AC $(20,28)$ may be that metaplastic changes take place in the epithelium when the congenitally sealed duct structures are slowly filled with secretions from the lining cells. This process may then lead to the expression of MUC5AC $(28,29)$. An alternative explanation would be that MNCs develop from duplicated gastrointestinal tissue, forming an enterogenic cyst (2). However, other features of intestinal mucosa, such as Paneth or goblet cells, that would support this assumption are completely lacking. Interestingly, there are cystic lesions in the liver that show similarities with MNC (30). The so-called solitary bile duct cyst is, like MNC, lined by cuboidal or columnar, sometimes mucin-producing, epithelium. However, this cystic lesion is only unilocular and therefore not fully comparable to MNC. Nevertheless, it may be related to MNC of the pancreas. Its pathogenesis is unclear. The other cystic lesion of the liver that has to be discussed in connection with MNC is biliary cystadenoma. This tumor, however, corresponds to the mucinous cystic neoplasm of the pancreas (21), which, as discussed earlier, clearly differs from MNC.

In summary, we have described a small series of previously unreported cystic lesions of the pancreas that show distinctive morphologic and immunocytochemical features setting them apart from all other cystic lesions and neoplasms of the pancreas (1). The only difficulties may arise in distinguishing them from MCN. This cystic tumor, which we named mucinous non-neoplastic cyst, follows a benign course. However, it seems that sudden bleeding into the MNC may complicate its course, as was seen in two of our cases. This in turn led to a sudden expansion of the MNC, causing obstruction of the nearby common bile duct and development of jaundice. The cause of the bleeding into the cyst is not known, but it seems that small vessels in the wall of the MNCs become more and more vulnerable when the cyst grows and the pressure on its wall increases.

Acknowledgments: We would like to thank Ms. Maike Pacena and Ms. Anja Paulus for their skillful technical assistance and Mrs. Kay Dege for editing the manuscript.

\section{REFERENCES}

1. Klöppel G, Kosmahl M. Cystic lesions and neoplasms of the pancreas: the features are becoming clearer. Pancreatology 2001;1:645-55.

2. Solcia E, Capella C, Klöppel G. Tumors of the pancreas. In: AFIP atlas of tumor pathology, 3rd series, Fascicle 20. Washington, DC: Armed Forces Institute of Pathology; 1997.

3. Adsay NV, Klimstra DS. Cystic lesions of the pancreas. Philadelphia: Saunders; 2000.

4. Klöppel G, Solcia E, Longnecker DS, Capella C, Sobin LH. Histological typing of tumours of the exocrine pancreas. 2nd 
ed. WHO international histological classification of tumours. Berlin: Springer; 1996.

5. Klöppel G. Pseudocysts and other non-neoplastic cysts of the pancreas. Semin Diagn Pathol 2000;17:7-15.

6. Adsay NV, Hasteh F, Cheng JD, Klimstra DS. Squamous-lined cysts of the pancreas: Lymphoepithelial cysts, dermoid cysts (teratomas) and accessory-splenic epidermoid cysts. Semin Diagn Pathol 2000;17:81-8.

7. Hruban RH, Adsay NV, Albores-Saavedra J, Compton C, Garrett ES, Goodman SN, et al. Pancreatic intraepithelial neoplasia. A new nomenclature and classification system for pancreatic duct lesions. Am J Surg Pathol 2001;25:579-86.

8. Klöppel G, Hruban RH, Longnecker DS, Adler G, Kern SE, Partanen TJ. Ductal adenocarcinoma of the pancreas. In: Hamilton SR, Aaltonen LA, editors. Pathology and genetics of tumours of the digestive system. WHO classification of tumours. Lyon, France: IARC Press; 2000. p. 221-30.

9. Longnecker DS, Adler G, Hruban RH, Klöppel G. Intraductal papillary-mucinous neoplasms of the pancreas. In: Hamilton SR, Aaltonen LA, editors. Pathology and genetics of tumours of the digestive system. WHO classification of tumours. Lyon, France: IARC Press; 2000. p. 237-40.

10. Fabre A, Sauvanet A, Fléjou JF, Belghiti J, Palazzo L, Ruzniewski P, et al. Intraductal acinar cell carcinoma of the pancreas. Virchows Arch 2001;438:312-15.

11. Fukushima N, Mukai K, Sakamoto M, Shimada K, Kosuge T, Kinoshita $\mathrm{T}$, et al. Invasive carcinoma derived from intraductal papillary-mucinous carcinoma of the pancreas: clinicopathologic and immunohistochemical study of 8 cases. Virchows Arch 2001;439:6-13.

12. Compagno J, Oertel JE. Mucinous cystic neoplasms of the pancreas with overt and latent malignancy (cystadenocarcinoma and cystadenoma). A clinicopathologic study of 41 cases. Am J Clin Pathol 1978;69:573-80.

13. Campbell JA, Cruickshank AH. Cystadenoma and cystadenocarcinoma of the pancreas. J Clin Pathol 1962;15:432-7.

14. Hodgkinson DJ, ReMine WH, Weiland LH. A clinicopathologic study of 21 cases of pancreatic cystadenocarcinoma. Ann Surg 1978;188:679-84.

15. Bogomoletz WV, Adnet JJ, Widgren S, Stavrou M, McLaughlin JE. Cystadenoma of the pancreas: a histological, histochemical and ultrastructural study of seven cases. Histopathology 1980;4:309-20.

16. Yamaguchi K, Enjoji M. Cystic neoplasms of the pancreas. Gastroenterology 1987;92:1934-43.

17. Wilentz RE, Albores-Saavedra J, Hruban RH. Mucinous cystic neoplasms of the pancreas. Semin Diagn Pathol 2000;17: 31-42.

18. Zamboni G, Scarpa A, Bogina G, Iacono C, Bassi C, Talamini $\mathrm{G}$, et al. Mucinous cystic tumors of the pancreas. Clinicopathological features, prognosis and relationship to other mucinous cystic tumors. Am J Surg Pathol 1999;23:410-22.
19. Osborn M, van Essen G, Weber K, Klöppel G, Altmannsberger M. Differential diagnosis of gastrointestinal carcinomas by using monoclonal antibodies specific for individual keratin polypeptides. Lab Invest 1986;55:497-504.

20. Moll R, Löwe A, Laufer J, Franke WW. Cytokeratin 20 in human carcinomas. A new histodiagnostic marker detected by monoclonal antibodies. Am J Pathol 1992;140:427-47.

21. Zamboni G, Klöppel G, Hruban RH, Longnecker DS, Adler G. Mucinous cystic neoplasms of the pancreas. In: Hamilton SR, Aaltonen LA, editors. Pathology and genetics of tumours of the digestive system. WHO classification of tumours. Lyon, France: IARC Press; 2000. p. 234-6.

22. Klimstra DS, Wenig BM, Heffess CS. Solid-pseudopapillary tumor of the pancreas: a typically cystic carcinoma of low malignant potential. Semin Diagn Pathol 2000;17:66-80.

23. Klöppel G, Lüttges J, Klimstra D, Hruban R, Kern S, Adler G. Solid-pseudopapillary neoplasm. In: Hamilton SR, Aaltonen LA, editors. Pathology and genetics of tumours of the digestive system. WHO classification of tumours. Lyon, France: IARC Press; 2000. p. 246-8.

24. Kosmahl M, Seada LS, Jänig U, Harms D, Klöppel G. Solidpseudopapillary tumor of the pancreas: its origin revisited. Virchows Arch 2000;436:473-80.

25. Capella C, Solcia E, Klöppel G, Hruban RH. Serous cystic neoplasms of the pancreas. In: Hamilton SR, Aaltonen LA, editors. Pathology and genetics of tumours of the digestive system. WHO classification of tumours. Lyon, France: IARC Press; 2000. p. 231-3.

26. Fléjou JF, Potet F, Molas G, Bernades P, Amouyal P, Fékété F. Cystic dystrophy of the gastric and duodenal wall developing in heterotopic pancreas: an unrecognized entity. Gut 1993; 34:343-7.

27. Ligneau B, Lombard-Bohas C, Partensky C, Valette PJ, Calender A, Dumortier J, et al. Cystic endocrine tumors of the pancreas: clinical, radiologic, and histopathologic features in 13 cases. Am J Surg Pathol 2001;25:752-60.

28. Lüttges J, Zamboni G, Longnecker D, Klöppel G. The immunohistochemical mucin expression pattern distinguishes different types of intraductal papillary mucinous neoplasms of the pancreas and determines their relationship to mucinous noncystic carcinoma and ductal adenocarcinoma. Am J Surg Pathol 2001;25:942-8.

29. Matsubayashi H, Watanabe H, Yamaguchi T, Ajioka Y, Nishikura K, Kijima $\mathrm{H}$, et al. Differences in mucus and K-ras mutation in relation to phenotypes of tumors of the papilla of Vater. Cancer 1999;86:596-607.

30. Ishak KG, Goodman ZD, Stocker JT. Tumors of the liver and intrahepatic bile ducts. In: AFIP atlas of tumor pathology, 3rd series, Fascicle 31. Washington, DC: Armed Forces Institute of Pathology; 2001. 